OPEN ACCESS

Edited by:

Guigen Li,

Texas Tech University, United States

Reviewed by:

Daniel Werz,

Technische Universitat Braunschweig,

Germany

Cunde Wang,

Yangzhou University, China

Xuegong She,

Lanzhou University, China

*Correspondence:

Hua Zhao

zhaohua@nbu.edu.cn

Hongbin Zhai

zhaihb@pkusz.edu.cn

Specialty section:

This article was submitted to

Organic Chemistry,

a section of the journal

Frontiers in Chemistry

Received: 18 May 2021 Accepted: 04 June 2021

Published: 16 July 2021

Citation:

Zhao $H$, Shen $P$, Sun $D$, Zhai $H$ and Zhao Y (2021) Transition-Metal-Free

[3+2] Dehydration Cycloaddition of Donor-Acceptor Cyclopropanes

With 2-Naphthols.

Front. Chem. 9:711257.

doi: 10.3389/fchem.2021.711257

\section{Transition-Metal-Free [3+2] Dehydration Cycloaddition of Donor-Acceptor Cyclopropanes With 2-Naphthols}

\author{
Hua Zhao ${ }^{1 *}$, Peng Shen ${ }^{1}$, Dongru Sun ${ }^{1}$, Hongbin Zhai ${ }^{2 *}$ and Yufen Zhao ${ }^{1}$ \\ ${ }^{1}$ Institute of Drug Discovery Technology, Ningbo University, Ningbo, China, ${ }^{2}$ State Key Laboratory of Chemical Oncogenomics, \\ School of Chemical Biology and Biotechnology, Shenzhen Graduate School of Peking University, Shenzhen, China
}

A Brønsted acid-catalyzed domino ring-opening cyclization transformation of donoracceptor (D-A) cyclopropanes and 2-naphthols has been developed. This formal [3+2] cyclization reaction provided novel and efficient access to the naphthalene-fused cyclopentanes in the absence of any transition-metal catalysts or additives. This robust procedure was completed smoothly on a gram-scale to afford the corresponding product with comparable efficiency. Furthermore, the synthetic application of the prepared product has been demonstrated by its transformation into a variety of synthetically useful molecules.

Keywords: donor-acceptor cyclopropane, 2-naphthol, brønsted acid, [3+2] cyclization, Naphthalene-fused cyclopentane

\section{INTRODUCTION}

The demands for effective assembly of diverse molecular scaffolds are continuously growing along with the development of organic chemistry. Among various methods, domino ring-opening cyclization has recently emerged as a powerful tool for the rapid build-up of molecular complexity (Bhattacharyya et al., 2016; Lin et al., 2017; Sayyad et al., 2017; Yi et al., 2018; Wan and Liu, 2019). As a versatile class of three-atom building blocks, donor-acceptor (D-A) cyclopropanes have experienced an unexpected renaissance in the last 2 decades, which are widely exploited in methodology as well as natural product synthesis (Cavitt et al., 2014; Schneider et al., 2014; Grover et al., 2015; Novikov, 2015; Reiser, 2016; Ivanova and Trushkov, 2019; Werz and Biju, 2020). Due to their property of formation of 1,3-zwitterion intermediates with the help of the ring strain, D-A cyclopropanes could enter multitudinous kinds of chemical transformations with different counterparts in organic synthesis. Among the multiple reactions, Lewis acid-catalyzed $(3+n)$ ring-opening cyclization of D-A cyclopropanes represent the most convenient method to form the carbocycles and heterocycles, such as $(3+2)$ cycloaddition with an unsaturated C-C multiple bond (Augustin et al., 2018; Ding et al., 2019; Huang et al., 2019; Mondal et al., 2019; Verma, et al., 2019; Xie et al., 2019), (3+3) cycloaddition with 1,3-dipoles (Dhote and Ramana, 2019; Petzold et al., 2019), and $(3+4)$ cycloaddition with conjugated dienes (Ivanova et al., 2008; Garve et al., 2016; Wang et al., 2017; Zhang et al., 2017; Augustin et al., 2019a; Li et al., 2020) (Scheme 1A). In addition, the basic transformation of D-A cyclopropanes usually focuses on straightforward ring-opening reactions with nucleophiles, which allows ready access to 1,3bifunctionalized derivatives (Garve et al., 2017; Lücht et al., 2017; Wallbaum et al., 2017; Das and DaniliucArmido, 2018; Augustin et al., 2019b; Lücht et al., 2019; Boichenko et al., 2020; Guin 
A Cycloaddition with double, triple bonds, 1,3-dipoles and conjugated dienes

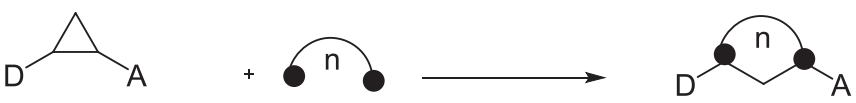

$2+3,3+3,4+3$

B Ring opening D-A cyclopropanes with nucleophiles<smiles>[R]C([N])CC([Y])F</smiles>

C Rearrangement reaction with itself

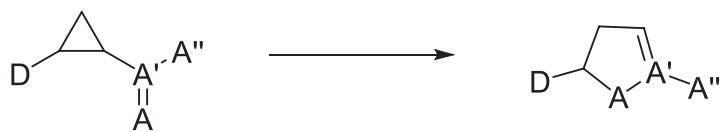

SCHEME 1 | Different types of reactions of D-A cyclopropanes.

1. previous work

A<smiles>[R]C#C[R]</smiles>

B

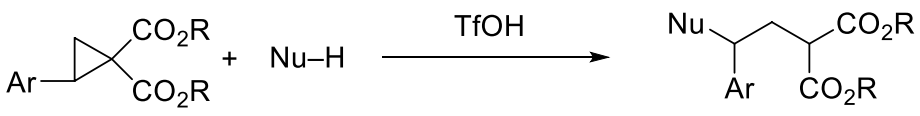

\section{2. this work}

C<smiles>[R1]c1ccc2cc(O)ccc2c1</smiles>

1<smiles>[R20]OCC1(O[R])CC1C=C</smiles>

2<smiles>[R2]OC(=O)C1(O[R])CCCC1</smiles>

transition-metal-catalyst free

$\mathrm{H}_{2} \mathrm{O}$ as the only by-product

low toxic and easily available $\mathrm{TfOH}$ catalyst

cyclopentane product with a versatile vinyl functional group

SCHEME 2 | The Brønsted acid-catalyzed reactions of D-A cyclopropanes.

et al., 2020) (Scheme 1B). Moreover, the unexpected rearrangement of D-A cyclopropanes could lead to partially unsaturated five-membered heterocycles (Ivanova et al., 2018; Ortega, 2018; Shim et al., 2018) (Scheme 1C).

Typically, all the catalytic systems of D-A cyclopropanes employ high loadings of Lewis acidic catalysts, usually rare- earth triflates, with the reactions typically operating at elevated temperatures. Compared with those of Lewis acid-catalyzed reactions, the Brønsted acid-catalyzed conversion of donoracceptor cyclopropanes has received only scant attention. In 2014, (3 + 2)-annulation of donor-acceptor cyclopropanes with alkynes induced by both Lewis and Brønsted acids was 


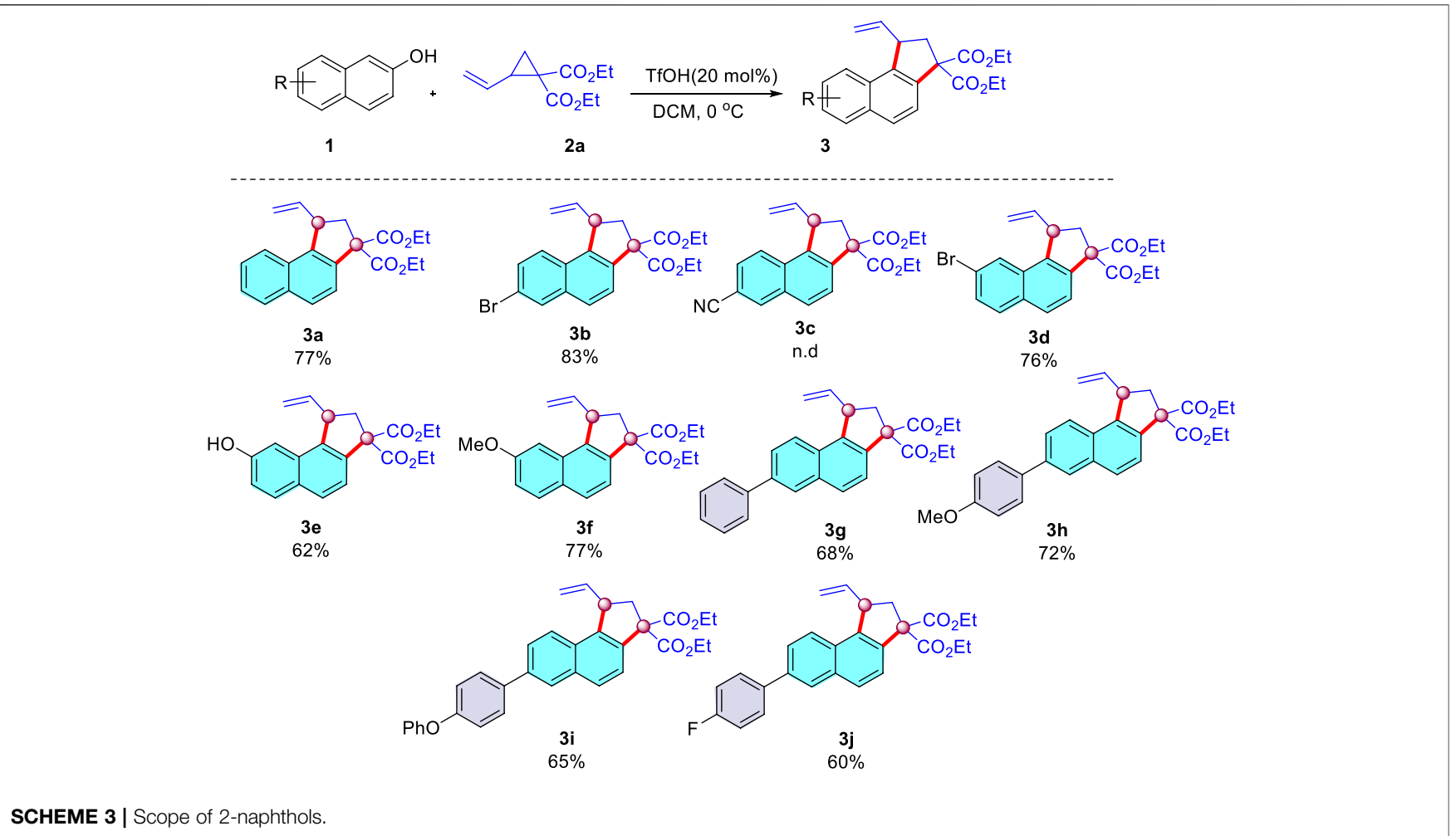

reported by Budynina (Rakhmankulov et al., 2015) (Scheme 2A). In 2018, Moran and co-workers presented an elegant nucleophilic ring opening of D-A cyclopropanes with nucleophiles in the presence of TfOH (Richmond et al., 2018) (Scheme 2B). Thus, developing sustainable alternative to achieve Brønsted acidcatalyzed reactions of donor-acceptor cyclopropanes is highly

TABLE 1 | Optimization of reaction conditions ${ }^{a}$.

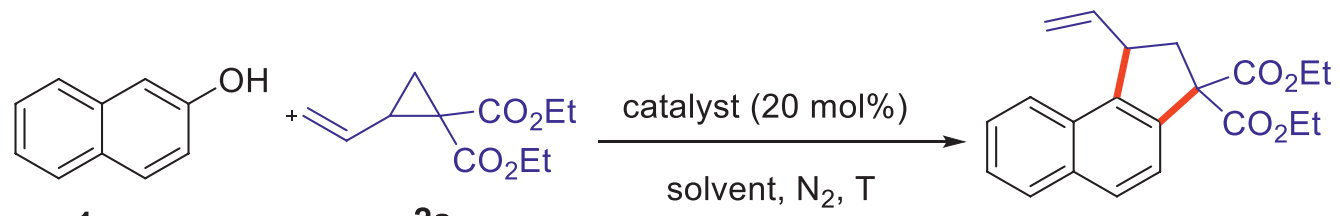

$1 \mathrm{a}$
$2 a$

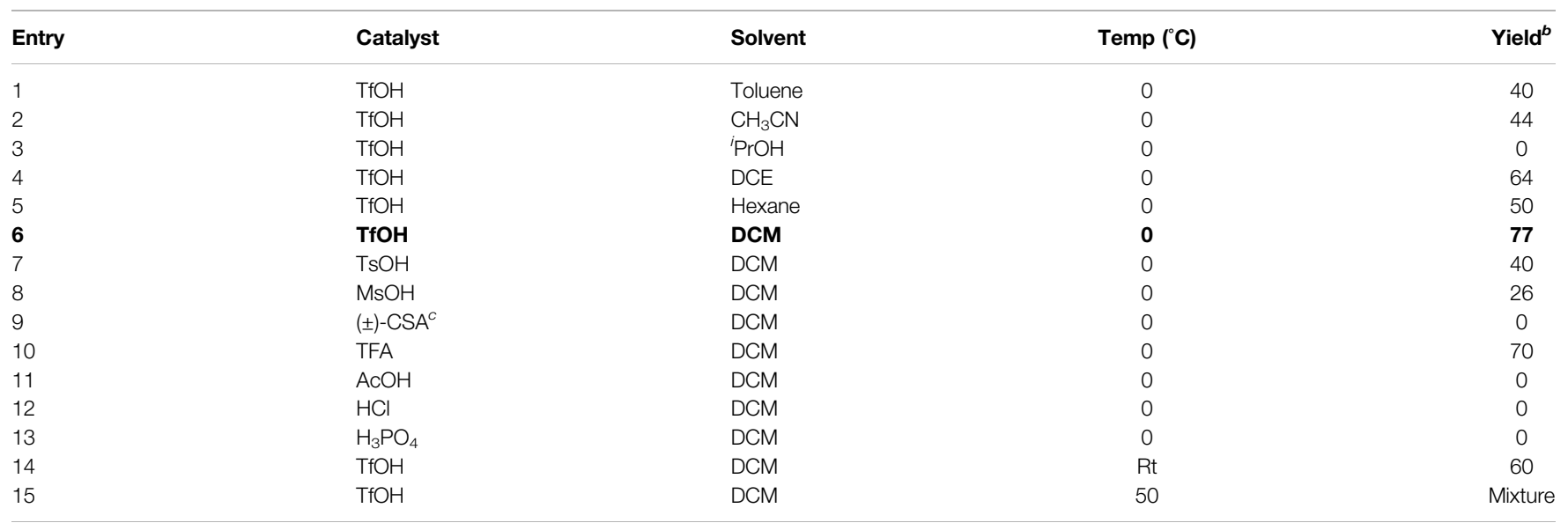

$3 a$

${ }^{a}$ Reaction conditions: Scheme 1A (0.20 mmol), Scheme 2A (0.3 mmol), catalyst (20 mol\%), solvent (1 $\left.\mathrm{ml}\right), \mathrm{N}_{2}, 0^{\circ} \mathrm{C}, 12 \mathrm{~h}$

b/solated yields.

${ }^{c}( \pm)-C S A=( \pm)$-Camphorsulfonic acid. 


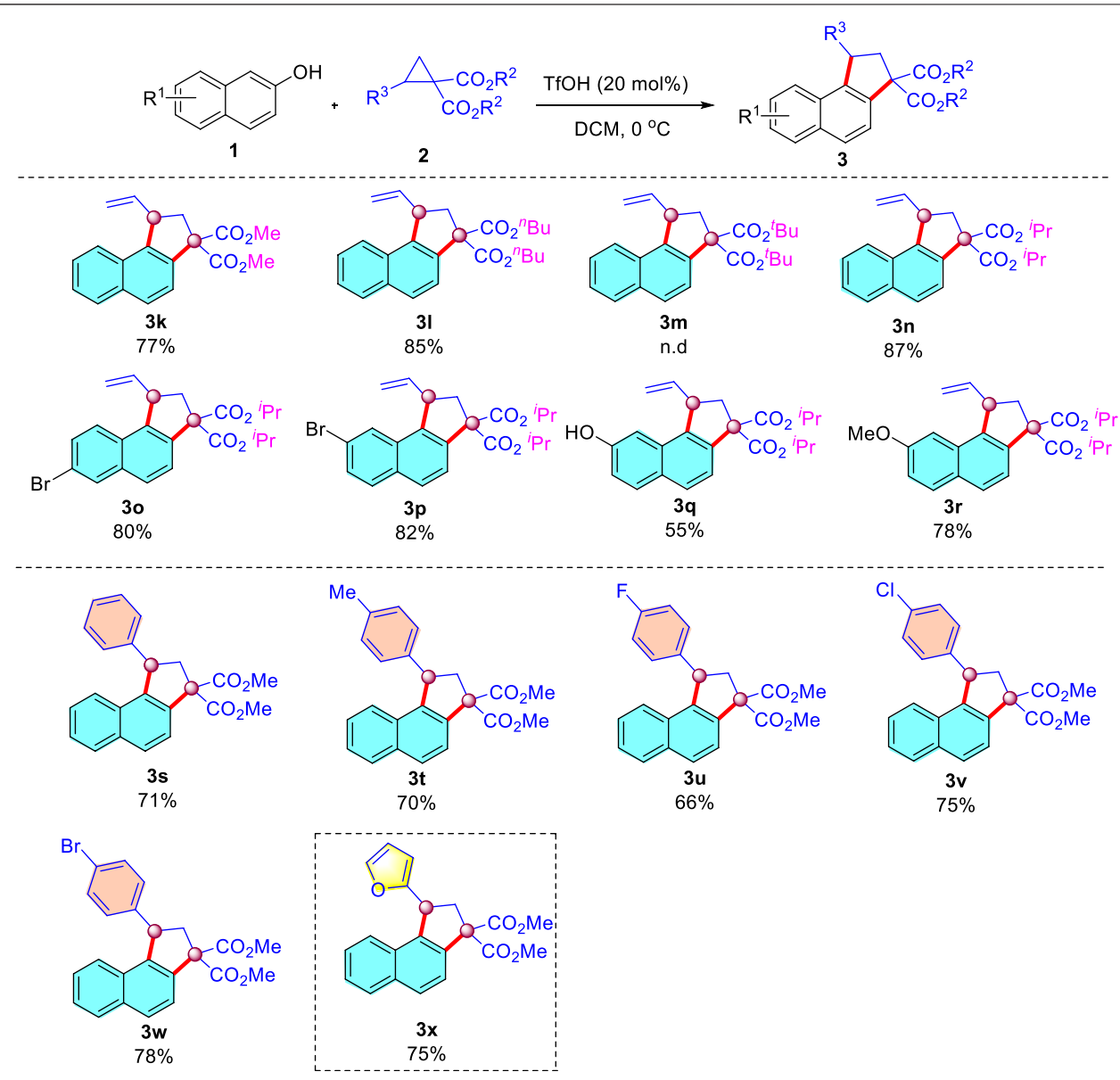

SCHEME 4 | Scope of donor-acceptor cyclopropanes.

desirable. We notice that 2-naphthols commonly serve as important aromatic feedstocks in organic chemistry (Zhuo and You, 2013; Wang et al., 2015; Yang et al., 2015; Zheng et al., 2015; Cheng et al., 2016; Shen et al., 2017; Tu et al., 2017; Fang et al., 2018; Liu et al., 2018; Xia et al., 2019; Zhang et al., 2020), and Biju disclosed a formal $(3+2)$ cyclopentannulation of 2-naphthols and $\mathrm{D}-\mathrm{A}$ cyclopropanes catalyzed by $\mathrm{Bi}(\mathrm{OTf})_{3}$ and $\mathrm{KPF}_{6}$ (Kaicharla et al., 2016). But in the case of a reaction involving D-A cyclopropanes with vinyl as the only substrate, the cyclization product is obtained in an unsatisfactory yield (42\%), which greatly inhibits the universality of the reaction. Given the versatility of the vinyl, here we report the successful realization of such a scenario, whereby $\mathrm{TfOH}$ acts as a highly active and general catalyst for the $(3+2)$ dehydration annulation of D-A cyclopropanes and 2-naphthols (Scheme 2C). The salient features of this transformation include: (a) the use of nonmetallic, low-toxicity, and easily available $\mathrm{TfOH}$ as the catalyst, (b) simple and benign reaction conditions in the absence of additives, (c) a broad substrate scope with respect to 2-vinylcyclopropane-1,1-dicarboxylate in moderate to high yields, beyond the yields and scope disclosed in the previous work, and (d) the resulting product is easily transformed into synthetically useful compounds.

\section{RESULTS AND DISCUSSION}

We commenced our investigation with 2-naphthol Scheme 1A and diethyl 2-vinylcyclopropane-1,1-dicarboxylate Scheme 2A as model substrates. To our delight, treatment of Scheme 1A and Scheme $2 \mathrm{~A}$ with $20 \mathrm{~mol} \%$ of $\mathrm{TfOH}$ without other additives in toluene at $0^{\circ} \mathrm{C}$ furnished the $(3+2)$ annulation product Scheme $\mathbf{3 A}$ in a $40 \%$ yield (Table $\mathbf{1}$, entry 1 ). Encouraged by the initial result, we then focused on solvent screening, and typical solvents including $\mathrm{CH}_{3} \mathrm{CN},{ }^{i} \mathrm{PrOH}$, DCE, hexane, and DCM were tested for the reaction (Table 1, entries 2-6). The results revealed that the solvents have great influence on the reaction outcome. Notably, DCM gave optimal results (77\% yield, Table 1, entry 6) while others led to low yields of Scheme 3A. Next, the evaluation of a series of Brønsted acids were conducted, such as $\mathrm{TsOH}, \mathrm{MsOH},( \pm)-\mathrm{CSA}, \mathrm{TFA}, \mathrm{AcOH}, \mathrm{HCl}, \mathrm{H}_{2} \mathrm{SO}_{4}$, and $\mathrm{H}_{3} \mathrm{PO}_{4}$. However, only under the catalysis of $\mathrm{TsOH}, \mathrm{MsOH}$, 
1. Gram-scale reaction

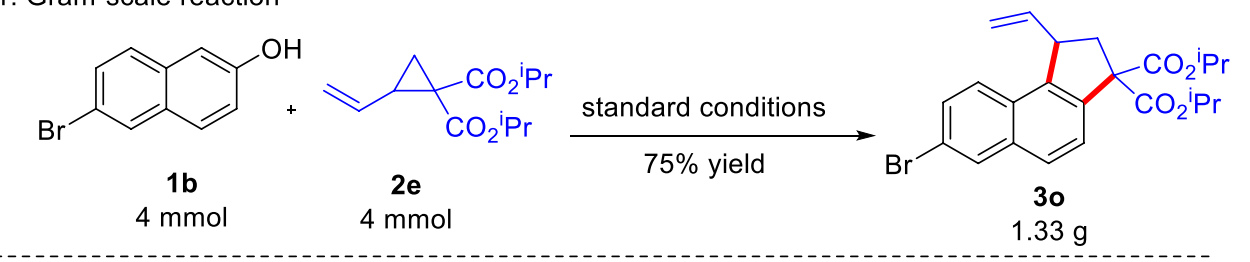

2. Allylation reaction of phenol and $\mathbf{2 a}$<smiles>Oc1ccccc1</smiles><smiles>C=CC1CC1(C(=O)OCC)C(=O)OCC</smiles><smiles>COC(C)O</smiles><smiles>CCOC(=O)C(C/C=C/Oc1ccc(O)cc1)C(=O)OCC</smiles>

SCHEME 5 | Gram-scale reaction and allylation reaction of phenol and 2-naphthol.

and TFA, the desired product was furnished at a $26-70 \%$ yield (Table 1, entries 7, 8, 10). Furthermore, efforts in running the reaction at room temperature proved to be unfruitful, as a slightly decreased yield (60\%) of Scheme $\mathbf{3 A}$ was observed, and a complex reaction system was obtained when elevating the reaction temperature to $50^{\circ} \mathrm{C}$ (Table 1, entries 12-13).

With the optimized conditions determined, the generality of substrates with respect to 2-naphthols was then explored. As summarized in Scheme 3, an array of 2-naphthols underwent successful cyclization with diethyl 2-vinylcyclopropane-1,1dicarboxylate Scheme 2A. First, 6-Br-2-naphthol was reacted with Scheme 2A, and the corresponding product Scheme 3B was obtained in an $83 \%$ yield. Whereas more electronwithdrawing cyano substituent decreased the performance of the reaction, providing almost no desirable product Scheme 3C. In addition, when the substrate with $\mathrm{Br}$ at the position of C7 of 2-naphthol was subjected to this reaction, it afforded Scheme $3 \mathrm{D}$ in a $76 \%$ yield. It is worth noting that when $2,7-$ dinaphthol bearing two reactive sites was chosen as the substrate, much to our surprise, monocyclic product Scheme 3E was isolated in a $62 \%$ yield. We speculated that a two-fold annulation product could be hampered by the unfavorable steric effect. Additionally, 2-naphthol with stronger electrondonating methoxy at the $\mathrm{C} 7$ position was also suitable for this reaction. Reaction of various 2-naphthol substrates bearing electron-donating or -withdrawing substituents at the phenyl residue provided the desired cyclization products in moderate to good yields (Schemes 3G-J, 60-72\%). It is fascinating that the phenoxyphenyl substituent was also suitable to this condition, leading to a $65 \%$ yield of Scheme 3I. The structure of the Schemes 3A-J were characterized by ${ }^{1} \mathrm{H},{ }^{13} \mathrm{C} \mathrm{NMR}$, and HRMS (See Supplementary Material).

Next, we moved our attention to explore the scope of donoracceptor cyclopropanes under the optimized conditions (Scheme 4). A series of 2-vinylcyclopropane-1,1-dicarboxylate (2, R = methyl, isopropyl, $n$-butyl) were compatible with the reaction conditions, leading to the corresponding dehydration annulation products in $77-87 \%$ yields. Unfortunately, D-A cyclopropane with tert-butyl shut down the desired transformation, presumably because the tert-butyl was readily hydrolyzed under strong acidic conditions. Similarly, when diisopropyl 2-vinylcyclopropane-1,1-dicarboxylate was reacted

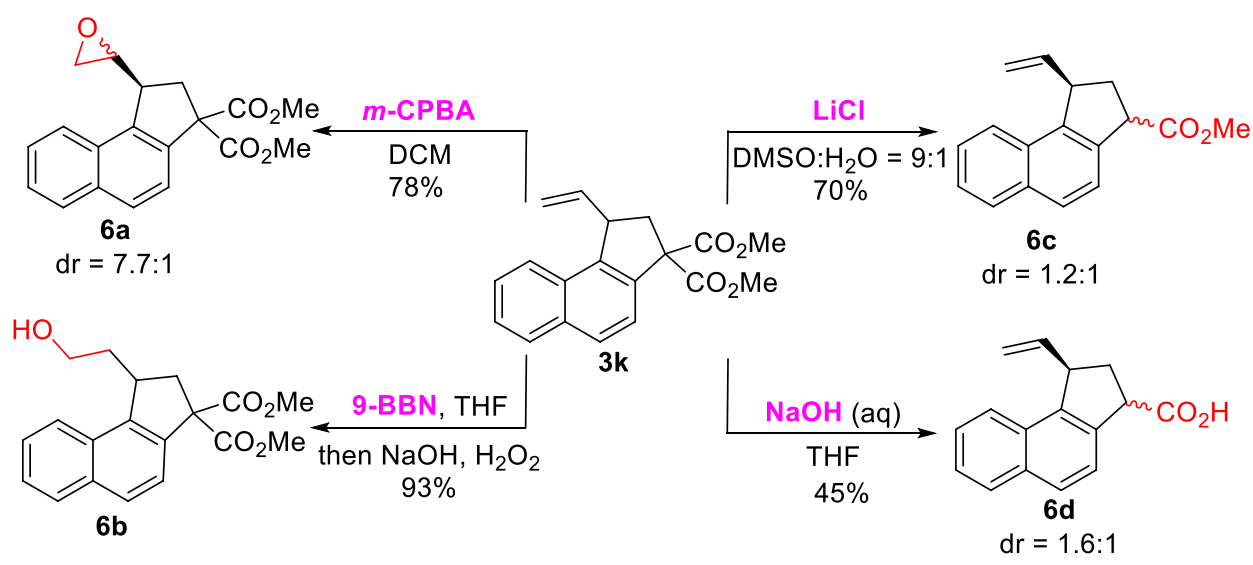

SCHEME 6 | Transformation of $\mathbf{3 k}$. 


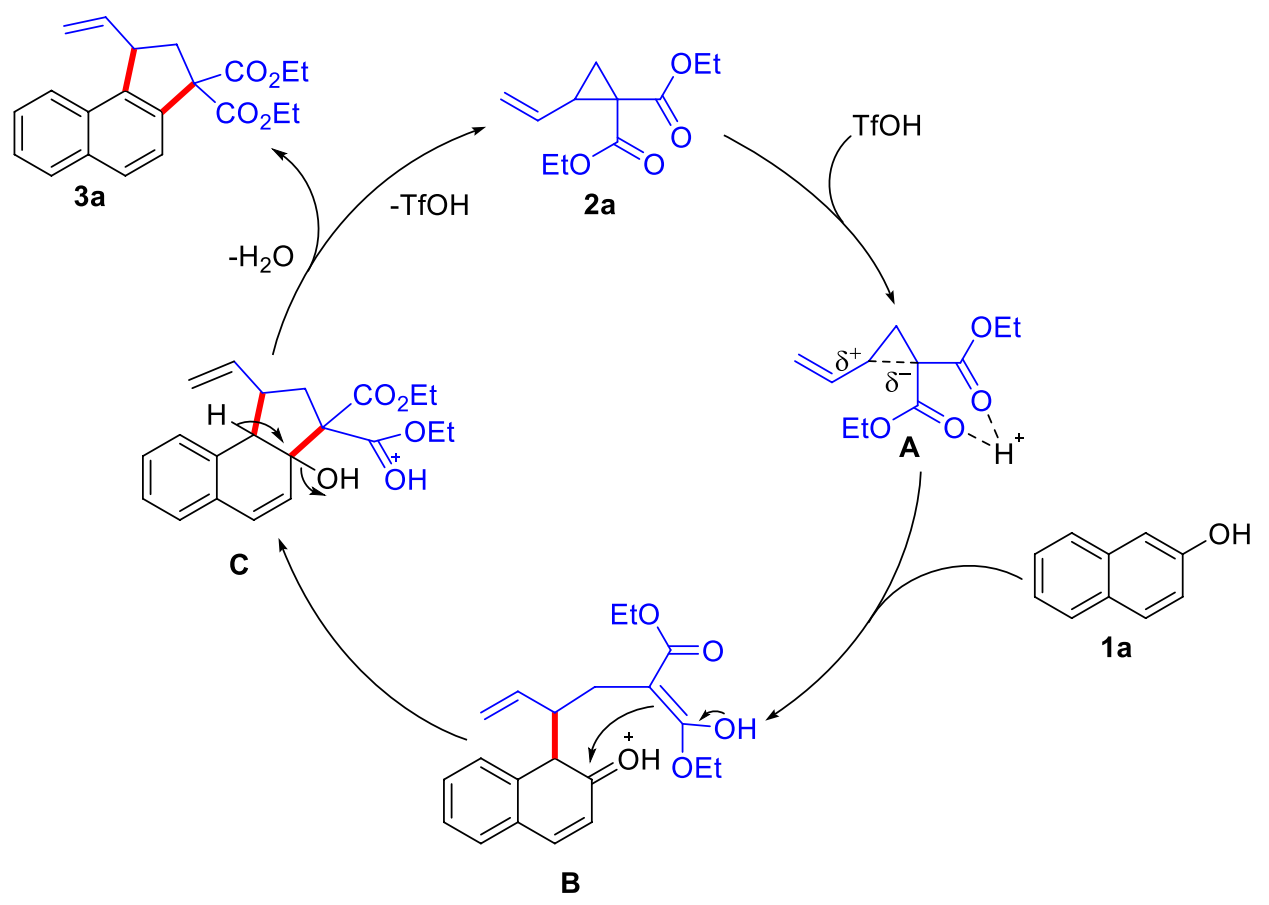

SCHEME 7| The proposed reaction mechanism.

with substituted 2-naphthols, the desired products were isolated in 55-82\% yields (Schemes 30-3R). In addition, aromatic donors such as phenyl residues in this protocol were also successful, and an electron-donating substituent attached to the aromatic backbone worked in a moderate yield (Scheme 3T, 70\% yield). Whereas more electron-withdrawing groups (F, $\mathrm{Cl}, \mathrm{Br}$ ) were also tolerated (Schemes 3U-W). Replacement of the benzene ring with a furan moiety in the substrate proved to be fine for the transformation (see Scheme 3X). The structure of the Schemes $3 \mathrm{~K}-\mathrm{X}$ were characterized by ${ }^{1} \mathrm{H},{ }^{13} \mathrm{C} \mathrm{NMR}$, and HRMS (See Supplementary Material).

Encouraged by the high efficiency of the domino ring-opening cyclization reaction of donor-acceptor cyclopropanes with 2naphthols, this TfOH-catalyzed reaction was completed smoothly on a gram-scale to afford the corresponding naphthalene-fused cyclopentane Scheme $\mathbf{3 0}$ with comparable efficiency (75\% yield, Scheme 5). Interestingly, an extraordinary ring-opening reaction initiated at the end of the double bond of D-A cyclopropane Scheme 2A could be accessed when phenol was used as the substrate, uncyclized product Scheme $\mathbf{5}$ was afforded in a $52 \%$ yield, which suggested that ring-opening occurred via an $\mathrm{S}_{\mathrm{N}} 2^{\prime}$-like mechanistic pathway. The structure of the Scheme $\mathbf{5}$ was characterized in the Supplementary Material.

To illustrate the application of this protocol, the transformation reactions with respect to product Scheme 3K were investigated (Scheme 6). First, efforts were focused on the versatile vinyl functional group, and the epoxidation of Scheme 3K with $m$-CPBA gave Scheme 6A in a $78 \%$ yield. In the presence of 9-BBN, Scheme $3 \mathrm{~K}$ underwent hydroboration-oxidation to deliver primary alcohol Scheme 6B (93\% yield). Furthermore, the treatment of Scheme $3 \mathbf{K}$ with $\mathrm{LiCl}$ in DMSO and $\mathrm{H}_{2} \mathrm{O}$ (9:1) furnished the selective decarboxylic product Scheme 6C in a $70 \%$ yield. Finally, the hydrolysis/decarboxylation reaction of Scheme 3K under an alkaline condition led to monocarboxyl product Scheme 6D in a $45 \%$ yield. The structure of the Schemes 6A-D were characterized by ${ }^{1} \mathrm{H},{ }^{13} \mathrm{C} \mathrm{NMR}$, and HRMS (See Supplementary Material).

Based on the previous report, we proposed a plausible mechanism of this Brønsted acid-catalyzed reaction (Scheme 7). Initial protonation of the "acceptor-motif" of cyclopropane Scheme $\mathbf{2 A}$ by $\mathrm{TfOH}$ possibly generates the intermediate $\mathbf{A}$, in which the polarization of $\mathrm{C}-\mathrm{C}$ bond increases. Ring-opening reaction of Scheme $\mathbf{1 A}$ to A generates the intermediate $\mathbf{B}$. The subsequent intermolecular aldol reaction generates the cyclopentane intermediate $\mathbf{C}$, which eliminates a molecule of water, and then forms the final product Scheme $\mathbf{3 A}$, along with the regeneration of the $\mathrm{TfOH}$ catalyst which enters the next catalytic cycle.

\section{CONCLUSION}

In summary, we have developed a robust strategy involving a Brønsted acid-facilitated domino ring-opening cyclization reaction, which provides efficient access to ubiquitous cyclopenta (a)naphthalene in moderate to good yields with high regioselectivity. Most importantly, this transformation avoids the use of metal-catalysts and external additives. Notably, a useful gram-scale reaction was completed smoothly via this protocol. Further applications involving Brønsted acid as 
a catalyst are under investigation in our laboratory and will be reported in due course.

\section{DATA AVAILABILITY STATEMENT}

The original contributions presented in the study are included in the article/Supplementary Material, further inquiries can be directed to the corresponding authors.

\section{AUTHOR CONTRIBUTIONS}

HuZ designed the work. HuZ and PS carried out the experimental part. HuZ, DS, HoZ, and YZ organized and wrote the manuscript.

\section{REFERENCES}

Augustin, A. U., Busse, M., Jones, P. G., and Werz, D. B. (2018). Formal Insertion of Thioketenes into Donor-Acceptor Cyclopropanes by Lewis Acid Catalysis. Org. Lett. 20, 820-823. doi:10.1021/acs.orglett.7b03961

Augustin, A. U., Jones, P. G., and Werz, D. B. (2019a). Ring-Opening 1,3Aminochalcogenation of Donor-Acceptor Cyclopropanes: A ThreeComponent Approach. Chem. Eur. J. 25, 11620-11624. doi:10.1002/ chem. 201902160

Augustin, A. U., Merz, J. L., Jones, P. G., Mlostoń, G., and Werz, D. B. (2019b). (4 + 3)-Cycloaddition of Donor-Acceptor Cyclopropanes with Thiochalcones: A Diastereoselective Access to Tetrahydrothiepines. Org. Lett. 21, 9405-9409. doi:10.1021/acs.orglett.9b03623

Bhattacharyya, A., Kavitha, C. V., and Ghorai, M. K. (2016). Stereospecific Synthesis of 2-Iminothiazolidines via Domino Ring-Opening Cyclization of Activated Aziridines with Aryl- and Alkyl Isothiocyanates. J. Org. Chem. 81, 6433-6443. doi:10.1021/acs.joc.6b01551

Boichenko, M. A., Andreev, I. A., Chagarovskiy, A. O., Levina, I. I., Zhokhov, S. S., Trushkov, I. V., et al. (2020). Ring Opening of Donor-Acceptor Cyclopropanes with Cyanide Ion and its Surrogates. J. Org. Chem. 85, 1146-1157. doi:10.1021/ acs.joc.9b03098

Cavitt, M. A., Phun, L. H., and France, S. (2014). Intramolecular Donor-Acceptor Cyclopropane Ring-Opening Cyclizations. Chem. Soc. Rev. 43, 804-818. doi:10.1039/c3cs60238a

Cheng, Q., Wang, Y., and You, S.-L. (2016). Chemo-, Diastereo-, and Enantioselective Iridium-Catalyzed Allylic Intramolecular Dearomatization Reaction of Naphthol Derivatives. Angew. Chem. Int. Ed. 55, 3496-3499. doi:10.1002/anie.201511519

Das, S., DaniliucArmido, C. G., and Studer, A. (2018). Lewis Acid Catalyzed Stereoselective Dearomative Coupling of Indolylboron Ate Complexes with Donor-Acceptor Cyclopropanes and Alkyl Halides. Angew. Chem. Int. Ed. 57, 4053-4057. doi:10.1002/anie.201711923

Dhote, P. S., and Ramana, C. V. (2019). One-Pot Au[III]-/Lewis Acid Catalyzed Cycloisomerization of Nitroalkynes and [3 +3$]$ Cycloaddition with DonorAcceptor Cyclopropanes. Org. Lett. 21, 6221-6224. doi:10.1021/ acs.orglett.9b02035

Ding, W.-P., Zhang, G.-P., Jiang, Y.-J., Du, J., Liu, X.-Y., Chen, D., et al. (2019). Electron-Deficient Alkynes as Dipolarophile in Pd-Catalyzed Enantioselective $(3+2)$ Cycloaddition Reaction with Vinyl Cyclopropanes. Org. Lett. 21, 6805-6810. doi:10.1021/acs.orglett.9b02431

Fang, X., Zeng, Y., Li, Q., Wu, Z., Yao, H., and Lin, A. (2018). Redox-Neutral AtomEconomic Pd(0)-Catalyzed Dearomatization of $\beta$-Naphthols with Alkynes toward Naphthalenones. Org. Lett. 20, 2530-2533. doi:10.1021/ acs.orglett.8b00662

Garve, L. K. B., Jones, P. G., and Werz, D. B. (2017). Ring-Opening 1-Amino-3Aminomethylation of Donor-Acceptor Cyclopropanes via 1,3-Diazepanes. Angew. Chem. Int. Ed. 56, 9226-9230. doi:10.1002/anie.201704619

Garve, L. K. B., Pawliczek, M., Wallbaum, J., Jones, P. G., and Werz, D. B. (2016). [4+3] Cycloaddition of Donor-Acceptor Cyclopropanes with Amphiphilic

\section{FUNDING}

We thank the National Natural Science Foundation of China (no. 22001137), Natural Science Foundation of Zhejiang Province (no. LQ20B020003), and Natural Science Foundation of Ningbo (no. 202003N4111) for financial support.

\section{SUPPLEMENTARY MATERIAL}

The Supplementary Material for this article can be found online at: https://www.frontiersin.org/articles/10.3389/fchem.2021.711257/ full\#supplementary-material

Benzodithioloimine as Surrogate for Ortho -Bisthioquinone. Chem. Eur. J. 22, 521-525, doi:10.1002/chem.201504013

Grover, H. K., Emmett, M. R., and Kerr, M. A. (2015). Carbocycles from DonorAcceptor Cyclopropanes. Org. Biomol. Chem. 13, 655-671. doi:10.1039/ c4ob02117g

Guin, A., Rathod, T., Gaykar, R. N., Roy, T., and Biju, A. T. (2020). Lewis Acid Catalyzed Ring-Opening 1,3-Aminothiolation of Donor-Acceptor Cyclopropanes Using Sulfenamides. Org. Lett. 22, 2276-2280. doi:10.1021/acs.orglett.0c00483

Huang, X.-B., Li, X.-J., Li, T.-T., Chen, B., Chu, W.-D., He, L., et al. (2019). Palladium-Catalyzed Highly Enantioselective Cycloaddition of Vinyl Cyclopropanes with Imines. Org. Lett. 21, 1713-1716. doi:10.1021/ acs.orglett.9b00274

Ivanova, O. A., Budynina, E. M., Grishin, Y. K., Trushkov, I. V., and Verteletskii, P. V. (2008). Donor-Acceptor Cyclopropanes as Three-Carbon Components in a [4+3] Cycloaddition Reaction with 1,3-Diphenylisobenzofuran. Angew. Chem. Int. Ed. 47, 1107-1110. doi:10.1002/anie.200704438

Ivanova, O. A., Chagarovskiy, A. O., Shumsky, A. N., Krasnobrov, V. D., Levina, I I., and Trushkov, I. V. (2018). Lewis Acid Triggered VinylcyclopropaneCyclopentene Rearrangement. J. Org. Chem. 83, 543-560. doi:10.1021/ acs.joc.7b02351

Ivanova, O. A., and Trushkov, I. V. (2019). Donor-Acceptor Cyclopropanes in the Synthesis of Carbocycles. Chem. Rec. 19, 2189-2208. doi:10.1002/ tcr.201800166

Kaicharla, T., Roy, T., Thangaraj, M., Gonnade, R. G., and Biju, A. T. (2016). Lewis Acid Catalyzed Selective Reactions of Donor-Acceptor Cyclopropanes with 2Naphthols. Angew. Chem. Int. Ed. 55, 10061-10064. doi:10.1002/ anie. 201604373

Li, B. Q., Qiu, Z.-W., Ma, A.-J., Peng, J.-B., Feng, N., Du, J.-Y., et al. (2020). Diastereoselective Synthesis of Cycloheptannelated Indoles via Lewis-AcidCatalyzed $(4+3)$-Cyclization of Donor-Acceptor Cyclopropanes. Org. Lett. 22, 1903-1907. doi:10.1021/acs.orglett.0c00248

Lin, T.-Y., Wu, H.-H., Feng, J.-J., and Zhang, J. (2017). Divergent Access to Functionalized Pyrrolidines and Pyrrolines via Iridium-Catalyzed DominoRing-Opening Cyclization of Vinyl Aziridines with $\beta$-Ketocarbonyls. Org. Lett. 19, 6526-6529. doi:10.1021/acs.orglett.7b03232

Liu, X., Wang, P., Bai, L., Li, D., Wang, L., Yang, D., et al. (2018). Construction of Vicinal All-Carbon Quaternary Stereocenters Enabled by a Catalytic Asymmetric Dearomatization Reaction of $\beta$-Naphthols with 3Bromooxindoles. ACS Catal. 8, 10888-10894. doi:10.1021/acscatal.8b03905

Lücht, A., Patalag, L. J., Augustin, A. U., Jones, P. G., and Werz, D. B. (2017). Reactions of Donor-Acceptor Cyclopropanes with Naphthoquinones: Redox and Lewis Acid Catalysis Working in Concert. Angew. Chem. Int. Ed. 56, 10587-10591. doi:10.1002/anie.201703732

Lücht, A., Sobottka, S., Patalag, L. J., Jones, P. G., Reissig, H. U., Sarkar, B., et al. (2019). New Dyes Based on Extended Fulvene Motifs: Synthesis through Redox Reactions of Naphthoquinones with Donor-Acceptor Cyclopropanes and Their Spectroelectrochemical Behavior. Chem. Eur. J. 25, 10359-10365. doi:10.1002/ chem.201900764

Mondal, M., Panda, M., McKee, V., and Kerrigan, N. J. (2019). Asymmetric Synthesis of Tetrahydrofurans through Palladium(0)-Catalyzed $[3+2]$ - 
Cycloaddition of Vinylcyclopropanes with Ketenes. J. Org. Chem. 84, 11983-11991. doi:10.1021/acs.joc.9b01854

Novikov, R. A., and Tomilov, Y. V. (2015). Dimerization of Donor-Acceptor Cyclopropanes. Mendeleev Commun. 25, 1-10. doi:10.1016/ j.mencom.2015.01.001

Ortega, A., Manzano, R., Uria, U., Carrillo, L., Reyes, E., Tejero, T., et al. (2018). Catalytic Enantioselective Cloke-Wilson Rearrangement. Angew. Chem. Int. Ed. 57, 8225-8229. doi:10.1002/anie.201804614

Petzold, M., Jones, P. G., and Werz, D. B. (2019). (3+3)-Annulation of Carbonyl Ylides with Donor-Acceptor Cyclopropanes: Synergistic Dirhodium(II) and Lewis Acid Catalysis. Angew. Chem. Int. Ed. 58, 6225-6229. doi:10.1002/ anie.201814409

Rakhmankulov, E. R., Ivanov, K. L., Budynina, E. M., Ivanova, O. A., Chagarovskiy, A. O., Skvortsov, D. A., et al. (2015). Lewis and Brønsted Acid Induced (3+2)Annulation of Donor-Acceptor Cyclopropanes to Alkynes: Indene Assembly. Org. Lett. 17, 770-773. doi:10.1021/ol5037562

Reiser, O. (2016). Catalytic Conversion of Furans and Pyrroles to Natural Products and Analogues Utilizing Donor-Acceptor Substituted Cyclopropanes as Key Intermediates. Isr. J. Chem. 56, 531-539. doi:10.1002/ijch.201500103

Richmond, E., Vuković, V. D., and Moran, J. (2018). Nucleophilic Ring Opening of Donor-Acceptor Cyclopropanes Catalyzed by a Brønsted Acid in Hexafluoroisopropanol. Org. Lett. 20, 574-577. doi:10.1021/acs.orglett.7b03688

Sayyad, M., Wani, I. A., Babu, R., Nanaji, Y., and Ghorai, M. K. (2017). A Synthetic Route to Chiral 1,4-Disubstituted Tetrahydro- $\beta$-Carbolines via Domino RingOpening Cyclization of Activated Aziridines with 2-Vinylindoles. J. Org. Chem. 82, 2364-2374. doi:10.1021/acs.joc.6b02719

Schneider, T. F., Kaschel, J., and Werz, D. B. (2014). A New Golden Age for DonorAcceptor Cyclopropanes. Angew. Chem. Int. Ed. 53, 5504-5523. doi:10.1002/ anie.201309886

Shen, D., Chen, Q., Yan, P., Zeng, X., and Zhong, G. (2017). Enantioselective Dearomatization of Naphthol Derivatives with Allylic Alcohols by Cooperative Iridium and Brønsted Acid Catalysis. Angew. Chem. Int. Ed. 56, 3242-3246. doi:10.1002/anie.201609693

Shim, S. Y., Choi, Y., and Ryu, D. H. (2018). Asymmetric Synthesis of Cyclobutanone via Lewis Acid Catalyzed Tandem Cyclopropanation/ Semipinacol Rearrangement. J. Am. Chem. Soc. 140, 11184-11188. doi:10.1021/jacs.8b06835

Tu, H.-F., Zheng, C., Xu, R.-Q., Liu, X.-J., and You, S.-L. (2017). Iridium-Catalyzed Intermolecular Asymmetric Dearomatization of $\beta$-Naphthols with Allyl Alcohols or Allyl Ethers. Angew. Chem. Int. Ed. 56, 3237-3241. doi:10.1002/ anie.201609654

Verma, K., Taily, I. M., and Banerjee, P. (2019). Exploitation of Donor-Acceptor Cyclopropanes and N-Sulfonyl 1-azadienes towards the Synthesis of spirocyclopentane Benzofuran Derivatives. Org. Biomol. Chem. 17, 8149-8152. doi:10.1039/c9ob01369e

Wallbaum, J., Garve, L. K. B., Jones, P. G., and Werz, D. B. (2017). Ring-Opening 1,3-Halochalcogenation of Cyclopropane Dicarboxylates. Org. Lett. 19, 98-101. doi:10.1021/acs.orglett.6b03375

Wan, S.-H., and Liu, S.-T. (2019). Functionalized Pyrroles from Vinylaziridines and Alkynes via Rhodium-Catalyzed Domino Ring-Opening Cyclization Followed by C C Bond Migration. Tetrahedron 75, 1166-1170. doi:10.1016/ j.tet.2019.01.022
Wang, S. G., Liu, X. J., Zhao, Q. C., Zheng, C., Wang, S. B., and You, S. L. (2015). Asymmetric Dearomatization of $\beta$-Naphthols through a BifunctionalThiourea-Catalyzed Michael Reaction. Angew. Chem. Int. Ed. 54, 14929-14932. doi:10.1002/anie.201507998

Wang, Z.-H., Zhang, H.-H., Wang, D.-M., Xu, P.-F., and Luo, Y.-C. (2017). Lewis Acid Catalyzed Diastereoselective [3+4]-annulation of Donor-Acceptor Cyclopropanes with Anthranils: Synthesis of Tetrahydro-1-Benzazepine Derivatives. Chem. Commun. 53, 8521-8524. doi:10.1039/c7cc04239f

Werz, D. B., and Biju, A. T. (2020). Uncovering the Neglected Similarities of Arynes and Donor-Acceptor Cyclopropanes. Angew. Chem. Int. Ed. 59, 3385-3398. doi:10.1002/anie.201909213

Xia, Z.-L., Zheng, C., Xu, R.-Q., and You, S.-L. (2019). Chiral Phosphoric Acid Catalyzed Aminative Dearomatization of $\alpha$-naphthols/Michael Addition Sequence. Nat. Commun. 10, 3150. doi:10.1038/s41467-019-11109-9

Xie, M.-S., Zhao, G.-F., Qin, T., Suo, Y.-B., Qu, G.-R., and Guo, H.-M. (2019). Thiourea Participation in [3+2] Cycloaddition with Donor-Acceptor Cyclopropanes: a Domino Process to 2-Amino-Dihydrothiophenes. Chem. Commun. 55, 1580-1583. doi:10.1039/c8cc09595g

Yang, D., Wang, L., Han, F., Li, D., Zhao, D., and Wang, R. (2015). Intermolecular Enantioselective Dearomatization Reaction of $\beta$-Naphthol UsingmesoAziridine: A Bifunctional In Situ Generated Magnesium Catalyst. Angew. Chem. Int. Ed. 54, 2185-2189. doi:10.1002/anie.201410257

Yi, R., Li, X., and Wan, B. (2018). Ring-opening and Cyclization of Aziridines with Aryl Azides: Metal-free Synthesis of 6-(triflyloxy)quinolines. Org. Chem. Front. 5, 3488-3493. doi:10.1039/c8qo00984h

Zhang, C., Tian, J., Ren, J., and Wang, Z. (2017). Intramolecular Parallel [4+3] Cycloadditions of Cyclopropane 1,1-Diesters with [3] Dendralenes: Efficient Construction of [5.3.0]Decane and Corresponding Polycyclic Skeletons. Chem. Eur. J. 23, 1231-1236. doi:10.1002/chem.201605190

Zhang, H.-J., Gu, Q., and You, S.-L. (2020). Ni-Catalyzed Allylic Dearomatization Reaction of $\beta$-Naphthols with Allylic Alcohols. Org. Lett. 22 (8), 3297-3301. doi:10.1021/acs.orglett.0c01109

Zheng, J., Wang, S.-B., Zheng, C., and You, S.-L. (2015). Asymmetric Dearomatization of Naphthols via a Rh-Catalyzed C(sp2)-H Functionalization/Annulation Reaction. J. Am. Chem. Soc. 137, 4880-4883. doi:10.1021/jacs.5b01707

Zhuo, C.-X., and You, S.-L. (2013). Palladium-Catalyzed Intermolecular Asymmetric Allylic Dearomatization Reaction of Naphthol Derivatives. Angew. Chem. Int. Ed. 52, 10056-10059. doi:10.1002/anie.201304591

Conflict of Interest: The authors declare that the research was conducted in the absence of any commercial or financial relationships that could be construed as a potential conflict of interest.

Copyright $\odot 2021$ Zhao, Shen, Sun, Zhai and Zhao. This is an open-access article distributed under the terms of the Creative Commons Attribution License (CC BY). The use, distribution or reproduction in other forums is permitted, provided the original author(s) and the copyright owner(s) are credited and that the original publication in this journal is cited, in accordance with accepted academic practice. No use, distribution or reproduction is permitted which does not comply with these terms. 